\title{
Characterization of epitopes involved in the neutralization of Pasteurella haemolytica serotype A1 leukotoxin
}

\author{
F. A. Lainson, J. Murray, R. C. Davies and W. Donachie \\ Author for correspondence: F. A. Lainson. Tel: +44131664 3262. Fax: +44 1316648001.
}

Moredun Research Institute, 408 Gilmerton Road, Edinburgh $\mathrm{EH} 17 \mathrm{JJH}$, UK

\begin{abstract}
Defined segments of the leukotoxin A gene ( $/ k t A)$ from an A1 serotype of Pasteurella haemolytica were cloned into a plasmid vector and expressed as LacZ $\alpha$ fusion proteins. These fusion proteins were electrophoresed in SDS-PAGE gels and their immunoblotting reactivities with several monoclonal antibodies characterized. The epitope recognized by a strongly neutralizing monoclonal antibody was localized to a 32 amino acid region near the $C$ terminus of the leukotoxin A (LktA) molecule. The epitope recognized by a non-neutralizing antibody was localized to a 33 amino acid region immediately adjacent. Smaller recombinant peptides containing these epitopes were not antigenic, but a polypeptide encompassing 229 amino acids at the $C$ terminus evoked neutralizing antibodies when used to immunize specific-pathogen-free lambs. The distributions of linear epitopes recognized by this antiserum and by antisera raised to full-length recombinant LktA and to native LktA produced by $P$. haemolytica serotype A1 were determined by their reactivities with a set of overlapping 10 amino acid synthetic peptides. This revealed a complex distribution of linear epitopes at the C-terminal end of LktA. Toxin-neutralizing antibodies in convalescent sheep serum were shown to be directed against conformational epitopes by selective absorption of antibodies directed against linear epitopes.
\end{abstract}

Keywords: Pastewrella baemolytica, epitope, leukotoxin A, RTX toxin

\section{INTRODUCTION}

Pasteurella baemolytica is a major respiratory pathogen of ruminants but, because it can exist as a commensal, it is frequently isolated from the upper respiratory tract of apparently healthy sheep and cattle. Although the conditions which cause it to become an invasive pathogen are not known, several virulence factors have been identified, including proteins involved in iton acquisition (Donachie \& Gilmour, 1988; Ogunnariwo \& Schryvers, 1990; Gilmour et al., 1991), outer membrane proteins (Donachie et al., 1984), lipopolysacchatide (Fenwick, 1990), capsular polysaccharide (Czuprynski et al., 1991a) and leukotoxin (LktA) (Lo et al., 1987).

Abbreviations: $I k t A(A 1)$ and $/ k t A(T 10)$, leukotoxin $A$ genes from Pasteurella haemolytica serotype A1 and Pasteurella trehalosi serotype T10, respectively; LktA(A1) and $L k t A(T 10)$, leukotoxin A gene products from $P$. haemolytica serotype $A 1$ and $P$. trehalosi serotype T10, respectively; SPF, specific-pathogen-free.

The GenBank accession number for the nucleotide sequence reported in this paper is $Z 26247$.
LktA is a potent cytolytic toxin secreted by both $P$. baemolytica and a closely related species Pasteurella trebalosi (Sneath \& Stevens, 1990). It is a member of the RTX (repeat in toxin) family of pore-forming cytolysins (Lo, 1995) which have been linked with the virulence of other bacterial species, for example Escberichia coli (Rowe et al., 1994) and Actinobacillus spp. (Frey, 1995). P. baemolytica Lkt $A$ is specific for ruminant leukocytes and is considered to be an important factor in establishing infection in the lung. It is believed to act in vivo by depleting the lung macrophage and neutrophil populations (Wilkie et al., 1990; Breider et al., 1991). Exposure to LktA also induces the release of oxygen-derived free radicals and proteolytic enzymes from neutrophils (Czuprynski et al., 1991b; Maheswaran et al., 1992) and histamine from bovine pulmonary mast cells (Adusu et al., 1994) which may contribute to a localized inflammatory response and tissue damage. In vitro, the cytolytic effects of LktA on bovine leukocytes can be abrogated by LktA-neutralizing antibodies, indicating that antibodies which neutralize LktA may provide a degree of protection against infection. The role of LktA in protective immunity is supported by 
successful vaccination and challenge experiments using specific-pathogen-free (SPF) lambs (Sutherland et al., 1989) and calves (Shewen et al., 1988; Conlon et al., 1991). The antigenic similarity between the toxins produced by different serotypes of $P$. baemolytica results in the production of cross-neutralizing antibodies (Shewen \& Wilkie, 1983). In ovine pasteurellosis this crossneutralizing effect offers an antigenic advantage in vaccine formulation where a range of serotypes are involved (Fraser et al., 1982).

Monoclonal antibodies with in vitro neutralizing activity against $P$. baemolytica LktA and the related toxin, $\alpha$ haemolysin, in $E$. coli have been reported (Gentry \& Srikumaran, 1991 ; Gerbig et al., 1992; Pellett et al., 1990). Monoclonal antibodies directed against a number of epitopes in the LktA molecule can differ widely in their capacity to neutralize LktA (Gerbig $e t$ al., 1992) suggesting that domains are present in the toxin which are important in antibody-mediated neutralization and that intact LktA may not be required to evoke a neutralizing antibody response. Vaccination with an antigen that contains defined epitopes would ensure that an immune response would be produced only to epitopes which are relevant to protective immunity and would thus allow experimental evaluation of the efficacy of defined recombinant polypeptides of LktA as vaccine components. For pasteurellosis of sheep, such an approach may also permit incorporation of several epitopes from a range of serotypes which are relevant to the disease in sheep (Gilmour \& Gilmour, 1989).

In the present study we investigated the epitopic structure of the $\mathrm{C}$ terminus of recombinant $\mathrm{LktA}$ and determined the ability of defined recombinant polypeptides derived from LktA to evoke production of toxin-neutralizing antibodies and hence their potential role as vaccine components.

\section{METHODS}

Strains and bacterial growth. $P$. baemolytica serotype A1 (strain SA1) and P. baemolytica serotype A2 (strain X205A) isolated from cases of ovine pneumonia, and $P$. trebalosi serotype T10 (strain 152/92) isolated from a case of systemic ovine pasteurellosis, were passaged on sheep blood agar and then stored at $-70^{\circ} \mathrm{C} . \mathrm{A} 1 \mathrm{ml}$ aliquot of frozen cells was grown at $37^{\circ} \mathrm{C}$ for $18 \mathrm{~h}$ in $50 \mathrm{ml}$ nutrient broth no. 2 (Gibco). This was used as seed for a 11 culture in nutrient broth no. 2 grown in a 21 flask for $5 \mathrm{~h}$ at $37^{\circ} \mathrm{C}$ on a rotary shaker. Bacterial cells were harvested by centrifugation at $10000 \mathrm{~g}$ and the pellets washed twice in PBS $(0.15 \mathrm{M} \mathrm{NaCl} / 0.01 \mathrm{M}$ sodium phosphate, $\mathrm{pH} 7 \cdot 4)$.

DNA manipulations. Genetic manipulations were carried out as described by Sambrook et al. (1989).

Cloning of restriction fragments of the $\mathbb{k t A}$ gene from $P$. haemolytica serotype A1 [iktA(A1)]. A series of constructs were made in which restriction fragments of plasmid pLkt52 (Lo et al., 1987) were subcloned into the multiple cloning site (MCS) of pUC8 for inducible expression of LktA or defined recombinant polypeptides derived from LktA (Fig. 1). Plasmid pAL2 contains a 3938 bp Bg/II fragment of pLkt52 (Fig. 1) cloned into the BamHI site of pUC8. In the remaining constructs, restriction fragments of the $l k t A$ gene were cloned into the pUC8 MCS for IPTG-inducible expression as fusion proteins with the LacZ peptide.

In pAL4, an MaeI fragment of the $1 k t A$ gene was isolated from construct pAL2, its blunt ends filled in using Klenow DNA polymerase I and then subcloned into the SalI site of pUC8 which was similarly filled in. Plasmids pAL6 and PAL7 were deletants prepared from pAL2. For pAL6, pAL2 was digested with $P s t I$ which cuts at two sites, one within $l k t A$ gene and the other in the PUC8 MCS; this construct was then ligated to circularize it. For construction of pAL7, pAL2 was digested at the $E_{c} \sigma \mathrm{RV}$ site within the $1 k t A$ gene and at the HindIII site within the MCS of pUC8; the blunt ends were filled in using Klenow polymerase and the construct ligated. For pAL.12, an EcoRV-HindIII fragment of pAL4 was isolated and then subcloned into the compatible HincII and HindIII sites of pUC8. For pAL14, a ClaI-HindIII fragment of pAL4 was subcloned into the compatible $A c i \mathrm{I}$ and HindIII sites of pUC8. Cloning and expression were as carried out in E. coli strain JM109.

Cloning of PCR-generated $\mathbf{l k t A}$ gene segments. Defined segments of $l k t . A$ DNA were generated by PCR using $\mathrm{PAL} 2$ template DNA. Oligonucleotide primers were constructed on the basis of the published sequence data of Lo et al. (1987) and Highlander $e t a l$. (1989). The primers (forward/reverse) used in each construct were: pAL27, 478M/479M; pAL28, 763M/ 479M; pAL29, 764M/479M; pAL32, 888A/311J; pAL34, 764M/222P; pAL35, 764M/311J; PAL36, 764M/973P. The nucleotide sequences of these oligonucleotides are shown in Table 1. Restriction sites were engineeted into the oligonucleotide primers to create an upstream EcoRI site in correct reading-frame alignment with the lac $Z^{\prime}$ gene start codon in pUC8 and a downstream HindIII site in correct reading-frame alignment with the alpha-fragment-encoding $\operatorname{lac} Z^{\prime} \mathrm{ORF}$. The PCR products were cloned into the EcoRI and HindIII sites of pUC8 to produce a series of $\Phi\left(l k t . A^{\prime}-l a c Z^{\prime}\right)(\mathrm{Hyb})$ derivatives and DNA sequence analyses carried out to confirm the identity of inserts. $\mathrm{Lkt}^{\prime} \mathrm{A}^{\prime}-\mathrm{LacZ} \alpha$ fusion proteins were expressed in $E$. coli strain JM109 from the IPTG-inducible lac promoter of pUC8. PAL32 made use of an upstream EcoR V site located within the lkt $A$ sequence (Fig, 1). The EcoRV-HindIII fragment was then cloned into the compatible HinclI and HindIII sites in pUC8.

Expression of recombinant LktA. For expression, cultures were grown to $\mathrm{OD}_{600} 0.5$ and then induced for $3 \mathrm{~h}$ with $0.5 \mathrm{mM}$ IPTG. Cells were harvested by centrifugation, washed twice in PBS, solubilized in SDS-PAGE sample buffer and then analysed by SDS-PAGE using $12 \%(\mathrm{w} / \mathrm{v})$ polyacrylamide gels and immunoblotting.

Cloning of the $\mathbf{k t A}$ gene from P. trehalosi serotype T10 [/ktA(T 10)]. The $1 k t A$ gene was isolated from a T'10 serotype genomic DNA library constructed in the vector lambda EMBL3 using a lkt $A(\mathrm{~A} 1) \mathrm{pAL} 2$ insert as a DNA probe. The nucleotide sequence of the $1 k t A(T 10)$ gene was determined using $T 7$ sequencing reagents (Pharmacia) and oligonucleotide primers (Oswel DNA Services).

SDSPAGE and immunoblotting. Recombinant LktA and Lkt $A^{\prime}-$ Lac $Z \alpha$ fusion proteins were analysed by SDS-PAGE on $12 \%$ polyacrylamide gels using prestained low-molecular-mass size standards from BioRad. Proteins were transferred electrophoretically onto Immobilon-P membranes (Millipore) using the method of Towbin et al. (1979). After blocking binding sites, the membranes were probed with monoclonal or polyclonal antibodies diluted to previously optimized concentrations. The appropriate species-specific anti-immunoglobulin, conjugated to horseradish peroxidase, was used according to the 
Table 1. PCR oligonucleotide primers used for generating defined DNA segments of $/ k t A$ for subcloning

\begin{tabular}{|cccc|}
\hline Primer & Direction & Location* & Nucleotide sequence \\
\hline $478 \mathrm{M}$ & Forward & $2682-2710$ & AAAAGTGAATTCTAACTATGAATTGCTCA \\
$763 \mathrm{M}$ & Forward & $2482-2508$ & ACGAAGAATTCAAAAGAGAAAGTGACC \\
$764 \mathrm{M}$ & Forward & $2362-2388$ & CACCGGAATTCCGATGGTAATGATAT'1 \\
$888 \mathrm{~A}$ & Forward & $467-488$ & GATTTAGATGAGGCCTTACA \\
$479 \mathrm{M}$ & Reverse & $2839-2865$ & AAAATAAGCTIGCTCTAGCAAATITGAA \\
$311 \mathrm{~J}$ & Reverse & $2503-2534$ & ATCAGCCAAGCTTAACCAGTTTTGAATGGTCA \\
$222 \mathrm{P}$ & Reverse & $2700-2729$ & GTCACAAAGCTTCTATGTTTGAGCAATTCA \\
$973 \mathrm{P}$ & Reverse & $2602-2630$ & ACTTGCAAGCTTGTGATCCGCTCGCCATT \\
\hline
\end{tabular}

* The location of oligonucleotides within the 1 tet $A$ gene $(2859$ bp) are shown (Lo et al., 1987). Nucleotide numbering begins with the first nucleotide of the start codon of lkt $A$.

† Sequences are shown from $5^{\prime}$ to $3^{\prime}$ ends; underlining shows the position of engineered restriction sites, EcoRI for forward primers and HindIII for reverse primers.

supplier's directions and the immunoblot developed using the substrate diaminobenzidine (Sigma).

Purification of recombinant LktA(A1) from $E$. coli strain JM109 containing plasmid pAL2. E. coli cells expressing PAL2encoded $\operatorname{LktA}(\mathrm{A} 1)$ were disrupted by sonication and centrifuged at $20000 \mathrm{~g}$ at $4{ }^{\circ} \mathrm{C}$. The resulting pellet (the LktAenriched fraction) was solubilized in $2 \%(\mathrm{w} / \mathrm{v})$ SDS and the solubilized material fractionated by gel filtration on Sephacryl S300 in PBS containing $0.1 \%$ SDS. Fractions containing the $105 \mathrm{kDa}$ protein were pooled. The protein was concentrated and further purified by absorption on to a hydroxyapatite BioGel HTP (BioRad) column in $10 \mathrm{mM}$ sodium phosphate buffer, $\mathrm{pH} 7.0$ containing $0.1 \%$ SDS and elution with a linear gradient of buffered phosphate from 0 to $0.5 \mathrm{M}$, $\mathrm{pH} 6.8$, containing $0.1 \%$ SDS. Eluates were monitored by SDS-PAGE and fractions containing almost pure $105 \mathrm{kDa}$ protein were pooled. SDS was removed by exhaustive dialysis against $50 \mathrm{mM}$ Tris $/ \mathrm{HCl}$ buffer, $\mathrm{pH} 7.6$, containing $1.0 \mathrm{mM}$ PMSF. The resulting $\operatorname{LktA}(\mathrm{A} 1)$ was $>90 \%$ pure as determined by SDSPAGE and immunoblots and contained $0.2 \mathrm{mg}$ protein $\mathrm{ml}^{-1}$.

Monoclonal antibodies. Ascitic fluids containing monoclonal antibody ( $\mathrm{mAb}$ ) MM601, which is strongly neutralizing and $\mathrm{mAb}$ MM605, which is non-neutralizing towards native LktA(A1) (Gentry \& Srikumaran, 1991), were obtained from Dr M. Gentry, University of Nebraska, Nebraska, USA.

Six monocional antibodies were produced in mice against recombinant LktA(A1) expressed from plasmid pAL2. Mice were immunized intraperitoneally with $25 \mu \mathrm{g}$ purified recombinant LktA in Freund's complete adjuvant and boosted 4 weeks later with the same preparation in Freund's incomplete adjuvant. Three days prior to hybridoma fusion two mice were boosted intravenously with $10 \mu \mathrm{g}$ immunizing antigen. For fusion, cells from homogenized spleens were fused with the mouse plasmacytoma SP-2 line in the presence of $\mathrm{PEG}$ according to the method of Kohler \& Milstein (1975). Wells containing hybridomas were screened for specific antibody against native $L k t A$ by ELISA. Cells secreting reactive antibody were then cloned by limiting dilution and the $\mathrm{mAbs}$ designated JM1 to JM6. Expression of anti-LktA antibody was confirmed by immunoblot analysis using recombinant LktA expressed from PAL2.

Polyclonal antibodies. SPF lamb antiserum to pAL2-encoded LktA was prepared by inoculating two 3-week-old SPF lambs intramuscularly with $100 \mu \mathrm{g}$ purified LktA antigen in $1 \mathrm{ml}$ $\mathrm{Al}(\mathrm{OH})_{3}$ on two occasions, 4 weeks apart. Serum was taken from the lambs before immunization and after the second vaccination.

Recombinant LktA'-LacZ $x$ fusion proteins expressed by pAL12, pAL34 and pAL36 were excised from polyacrylamide gels after SDS-PAGE separation and the identity of the excised fusion polypeptide confirmed by immunoblot analysis using mAb MM601. For inoculation, this material was treated as described by Murray et al. (1992). pAL12-encoded antigen was used to immunize SPF lambs, and PAL34- and pAL36-encoded antigens were used to immunize rabbits.

Antiserum S791 was raised in SPF lambs by acrosol administration of $P$. baemolytica serotype A2. Sera were taken from surviving lambs 3 weeks later and pooled. This was regarded as convalescent antiserum. Antiserum SA1 was raised in a conventionally reared sheep with no anti-LktA titre. The sheep was inoculated subcutaneously with washed $P$. haemolytica serotype A1 cells from a $6 \mathrm{~h}$ culture in nutrient broth. The sheep was bled 2 weeks after inoculation and the serum stored at $-20^{\circ} \mathrm{C}$.

LktA cytotoxicity assay and neutralization test. Cell culture supernatant fraction from serotype A1 cells in early exponential phase $(1-3 \mathrm{~h})$ in RPMI medium containing either $7 \%(\mathrm{v} / \mathrm{v})$ foetal bovine serum (FBS) or $5 \mathrm{mg} \mathrm{BSA} \mathrm{ml}{ }^{-1}$ was filtered through a $0.22 \mu \mathrm{m}$ membrane, dialysed and freeze-dried in $1 \mathrm{ml}$ aliquots. Stock toxin was prepared by dissolving freeze-dried material in Hank's phosphate buffered saline (PBS) containing $7 \%$ FBS and mixed with either sheep macrophages or bovine lymphoma (BL3) cells at $10^{7}$ cells $\mathrm{ml}^{-1}$ in Hank's PBS at room temperature for $1 \mathrm{~h}$. Cytotoxicity was measured by a Trypan blue exclusion test in which the percentage of dead cells was estimated by microscopic examination. For neutralization tests, toxin was mixed with doubling dilutions of antibody for $15 \mathrm{~min}$ at room temperature and then added to the target cells for $1 \mathrm{~h}$. Lysis of cells was again tested by the Trypan blue exclusion test. An alternative cytotoxicity test (Cell Titer 96, Promega) was used to monitor the absorption of antisera. This test is based on the reduction of a soluble tetrazolium dye by BL3 cells in Hank's PBS, FBS at room temperature. Dye reduction was monitored at $A_{490}$.

Antibody absorption. Lyophilized LktA-entiched fraction $(0.5 \mathrm{mg})$ of an E. coli (pAL2) lysate was suspended in $100 \mu \mathrm{l}$ $10 \mathrm{mM}$ Tris/HCl buffer, $\mathrm{pH} 70$, containing $5 \%$ SDS and $5 \%$ 
$(\mathrm{v} / \mathrm{v}) \beta$-mercaptoethanol and then heated to $100^{\circ} \mathrm{C}$. This solution was diluted to $10 \mathrm{mi}$ in $10 \mathrm{mM}$ Tris/ $\mathrm{HCl}, \mathrm{pH} 7.0$ and the antigen adsorbed onto Immobilon-P membranes (Millipore) at room temperature with shaking for $2 \mathrm{~h}$. The efficiency of adsorption was monitored by an immunoblot reaction with mAb MM601 using a section of the membrane. The membrane was washed extensively in $10 \mathrm{mM}$ Tris/ $\mathrm{HCl}$ buffer, $\mathrm{pH} 7 \cdot 5$, containing $0.05 \%$ Tween. Strips of approximately $7 \mathrm{~cm}^{2}$ were used to absorb antibodies from $10 \mathrm{ml}$ aliquots of SA1 and $\mathrm{S} 791$ antisera, respectively, each diluted $1 / 40$ in PBS. The immunoblotting reaction with recombinant $\mathrm{Lkt}$ antigen and the neutralizing capacity of both antisera were determined before absorption and after each of four sequential absorptions carried out at room temperature.

Peptide synthesis and epitope screening. Peptides were synthesized on a solid phase using a modification of the method of Geysen et al. (1987). Reagents were supplied by Cambridge Research Biochemicals. Overlapping synthetic peptides were constructed on the basis of the published sequence data for $P$. baemolytica serotype A1 (Lo at al., 1987). The region of LktA investigated extended from amino acid 722 to the $C$ terminus of LktA, amino acid 953. Synthesized peptides were 10 amino acids long and the start point for each successive peptide was progressed by 3 amino acid residues. Duplicate peptides were screened with various antisera using an ELISA with horseradish peroxidase conjugated to various anti-species immunoglobulin. Absorbance was measured at $405 \mathrm{~nm}$.

\section{RESULTS}

\section{Characteristics of anti-LktA antibodies}

In tests using the Trypan blue method to determine neutralizing tittes, $\mathrm{mAb}$ MM601 had a neutralizing titre of $>1 / 4000$, whereas mAb MM605 failed to neutralize at a dilution of $1 / 10$. mAbs JM1-JM6 gave strong immunoblotting reactions at a dilution of $1 / 40$ but no neutralization could be detected in undiluted hybridoma supernatants. The polyclonal antibodies S791 and SA1 had neutralizing titres of $1 / 400$ and $1 / 4000$, respectively.

\section{Epitope mapping reveals the position of an epitope concerned with toxin neutralization}

Defined segments of the lkt $A(A 1)$ gene were subcloned in pUC8 for expression of LktA-derived polypeptides as Lac $Z \alpha$ fusion proteins. The reactivities of these expressed proteins with various antibodies were determined by immunoblotting (Fig. 1). The epitopes recognized by neutralizing $\mathrm{mAb}$ MM601 and non-neutralizing $\mathrm{mAb}$ MM605, and also by the six monoclonal antibodies JM1-JM6 (data not shown), all lay within a 229 amino acid region (722-950) at the C-terminal end of LktA. This is defined by the positive reaction of these $\mathrm{mAbs}$ with the LktA-derived product expressed from plasmid pAL12. More detailed mapping of this region relied on cloning and expression of DNA subclones generated by PCR (Fig. 2). The epitope for mAb MM601 was mapped to a 32 amino acid region on the basis of its reaction with LktAderived polypeptides expressed from plasmids pAL36 and pAL28, but not with those expressed from plasmids pAL35 or PAL32. The epitope for MM605 was mapped to a 33 amino acid region immediately downstream on the basis of its reaction with the LktA-derived polypeptide expressed from pAL34 but not with that expressed from pAL36. Controls included in the immunoblotting procedure showed that none of the mAbs used reacted with

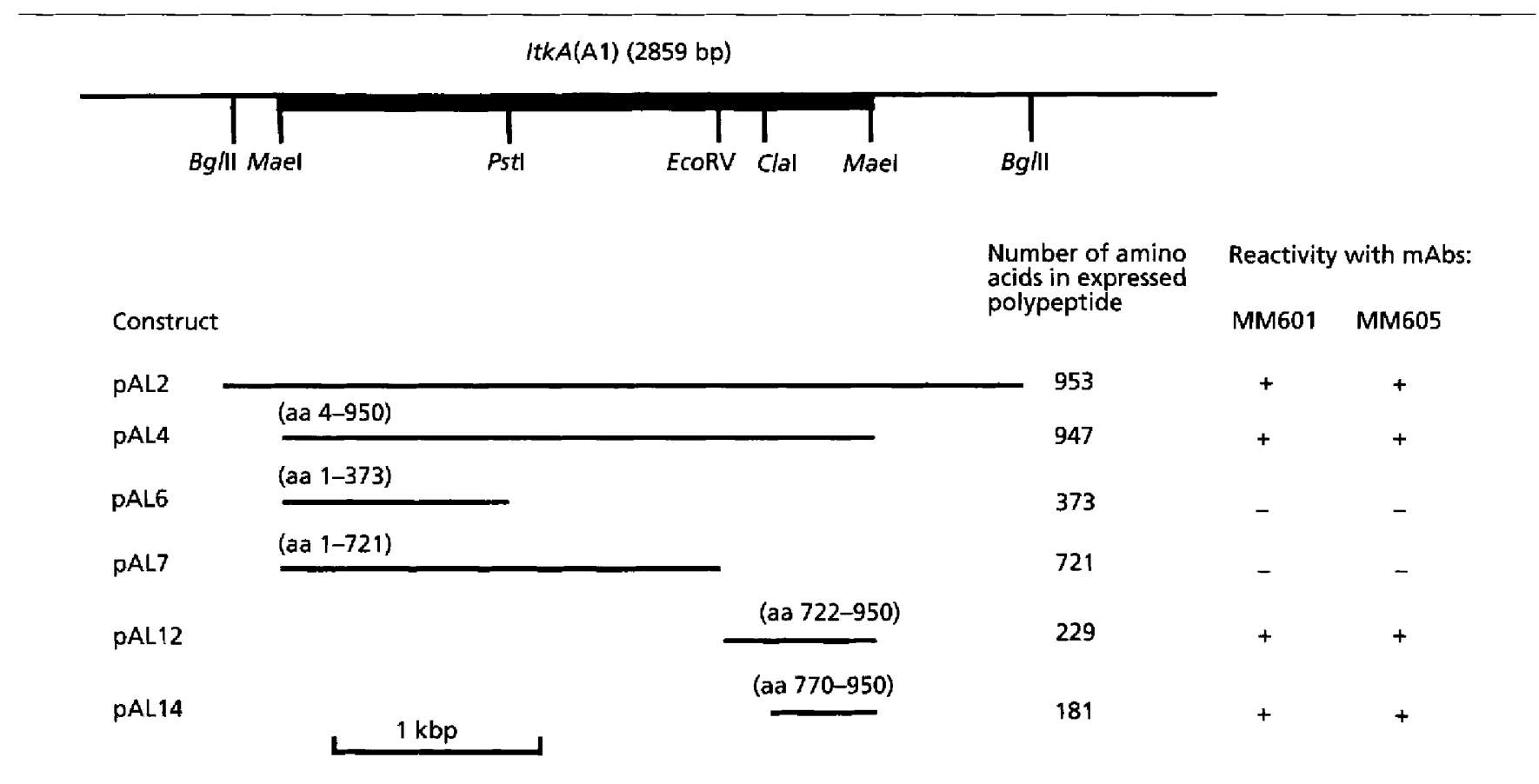

Fig. 1. Immunoblot reactions of mAbs MM601 and MM605 with LktA(A1) and LktA(A1)-derived polypeptides expressed from $1 k t A$ subclones in pUC8 constructs in $E$. coli. The filled box represents the ORF for the $I k t A$ gene. Each construct is shown, together with the amino acid region spanned by the expressed LktA(A1)-derived polypeptide and its size. Positive $(+)$ and negative $(-)$ reactions are indicated. 

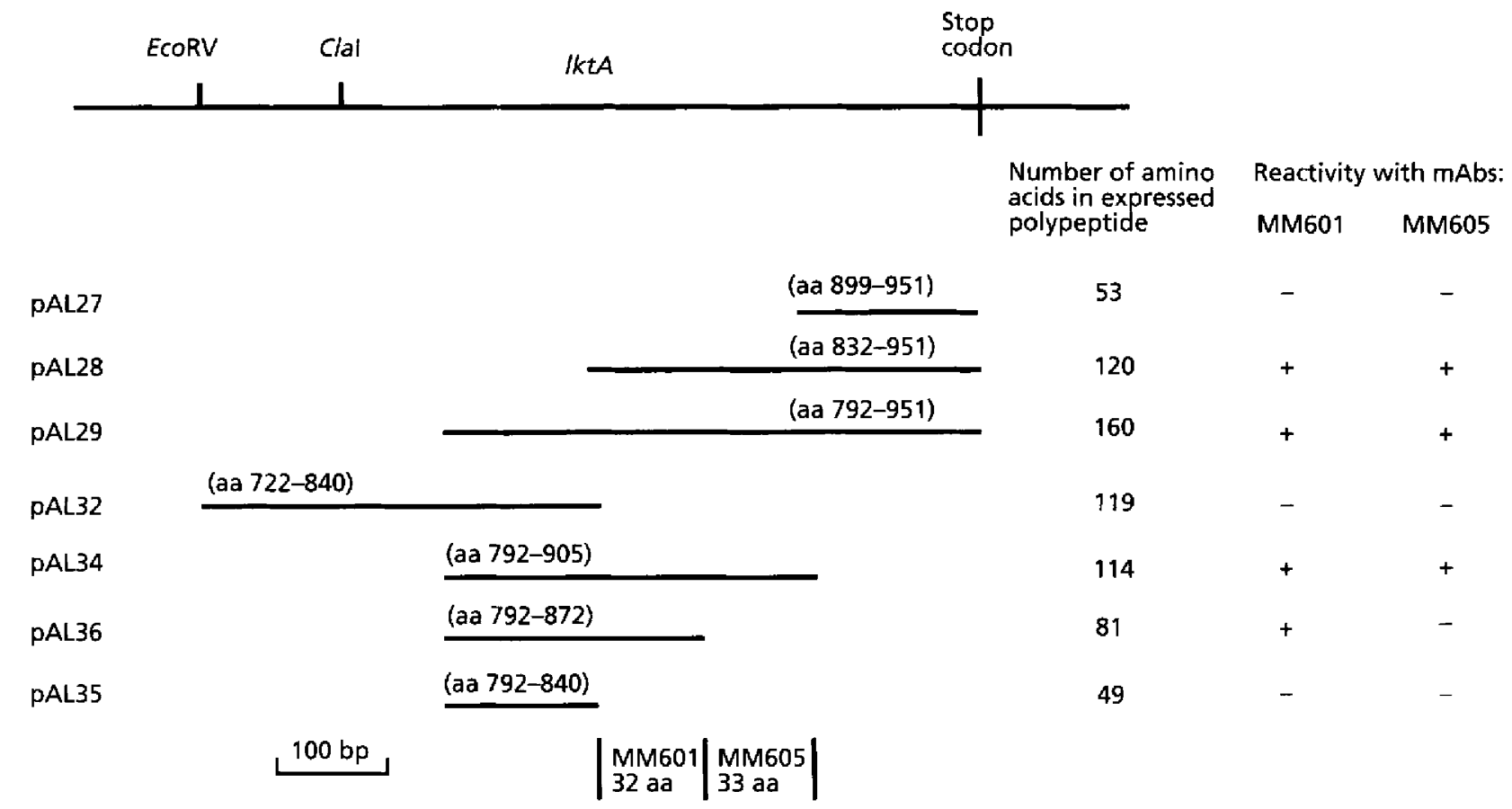

Fig. 2. Immunoblot reactions of mAbs MM601 and MM605 with LktA(A1)-derived polypeptides encoded by PCRgenerated DNA segments of $I k t A$ cloned into pUC8 and expressed in $E$. coli. Each plasmid construct is shown together with the amino acid region spanned by the expressed LktA-derived polypeptide and its size. Positive $(+)$ and negative $(-)$ reactions are indicated.

E. coli lysates or with the LacZ $\alpha$ component of the fusion protein.

\section{Comparison with LktA(T10)}

The mAbs MM601 and MM605 did not react with LktA(T10) on immunoblots and did not neutralize LktA(T10) in vitro. This lack of cross-reactivity is probably due to amino acid sequence differences within the linear epitopes recognized by these antibodies between the Lkt $A$ s produced by $A 1$ and $T 10$ serotype strains. We cloned and determined the nucleotide sequence of the lkt $A$ gene from a T10 serotype strain of P. trebalosi. The deduced amino acid sequences of the C-terminal 205 amino acids of A1 and T10 serotypes are shown in Fig. 3. The positions of the epitopes recognized by the $\mathrm{mAbs}$ MM601 and MM605, as determined by the mapping experiments described above, are indicated. Comparison of these amino acid sequences confirmed that differences exist in the regions of both epitopes and further localized the A1 epitopes to positions where the amino acid sequences of the $A 1$ and T10 toxins differed.

\section{Antigenicity of expressed LktA(A1)-derived recombinant polypeptides}

E. coli(pAL2) expressed the full-length LktA(A1) molecule (953 amino acids) in a biologically inactive form. $E$. coli cells bearing pAL12 expressed a Lkt $A^{\prime}-$ Lac $Z \alpha$ fusion protein which encompassed 229 amino acids at the
C-terminal end of IktA(A1) (Fig. 1). After partial purification by gel filtration, these proteins were used to immunize SPF lambs. The antisera obtained were strongly reactive against full-length recombinant $\mathrm{LktA}$ on immunoblots and had a LktA-neutralizing titre of $>256$ as determined by the Trypan blue method. E. coli bearing plasmids pAL34 and pAL36 (Fig. 2) expressed smaller Lkt $A^{\prime}$ peptides as fusion proteins which encompassed the epitopes recognized by both mAb MM601 (neutralizing) and $m A b$ MM 605 (non-neutralizing) and by mAb MM601 alone, respectively. Bands containing these fusion peptides, which had been excised from SDS-PAGE gels, were used to immunize rabbits but neither fusion peptide elicited an antibody response that could be detected by immunoblot analysis using pAL2- or pAL12-encoded antigen.

\section{Epitope mapping of the $C$ terminus of LktA using synthetic peptides}

mAb MM601 did not react with any of the 7510 amino acid synthetic peptides produced on a solid support. However, various antisera directed against LktA(A1) did react, and identified several potential linear B-cell epitopes located near the $C$ terminus of LktA (Fig. 4). Although relative peak heights were different, similar profiles were obtained for each of the antisera tested, namely, polyclonal antiserum raised in an SPF lamb against the C-terminal fragment of recombinant LktA(A1) expressed from plasmid pAL12 (anti-LktA') (Fig. 4b), polyclonal anti- 
749 RLFGGKGDDI LDGGNGDDFI DGGKGNDLLH GGKGDDIFVH RKGDGNDIIT DSDGNDKLSF SDSNLKDLTF EKVKHNLVIT

$$
\text { I } \quad Q \quad S \quad E E \quad N H
$$

829 NSKKEKVTIQ NWEREADFAK EVRNYKATKD EKIEEIIGQN GERITSKQVD DLIAKGNGKI TQDELSKVVD NYELLKHSKN
$T^{2} Q$

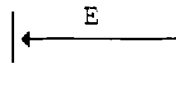
Neutralizing mAb M601 $\rightarrow$

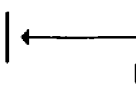
E $E \quad$ A S T
Non-neutralizing mAb MM605

909 VTNSLDKLIS SVSAFTSSND SRNVLVAPTS MLDQSLSSLQ FARAA*
As
AS
P I

Fig. 3. Comparison of the amino acid sequences (residues 749-953) of LktA(A1) and LktA(T10). The LktA(A1) sequence is shown in full; where the LktA(T10) sequence differs, the substituted amino acid is shown. The location of epitopes for the neutralizing (MM601) and the non-neutralizing (MM605) mAbs are indicated. The C terminus of LktA is indicated by an asterisk.

(a)

\begin{tabular}{cc}
$\begin{array}{c}\text { Peptide } \\
\text { number }\end{array}$ & Peptide \\
sequence \\
1 & IFKGSKFNDA \\
2 & GSKFNDAFNG \\
3 & FNDAFNGGDG \\
4 & AFNGGDGVDT \\
5 & GGDGVDTIYG \\
6 & GVDT IYGNDG \\
7 & TIYGNDGNDR \\
8 & GNDGNDRLFG \\
9 & GNDRIFGGKG \\
10 & RLFGGKGDDI \\
11 & GGKGDDILDG \\
12 & GDDILDGGNG \\
13 & ILDGGNGDDF \\
14 & GGNGDDFIDG \\
15 & GDDFIDGGKG \\
16 & FIDGGKGNDL \\
17 & GGKGNDLLHG \\
18 & GNDLLHGGKG \\
19 & LLHGGKGDDI \\
20 & GGKGDDI FVH \\
21 & GDDIFVHRKG \\
22 & IFVHRKGDGN \\
23 & HRKGDGNDII \\
24 & GDGNDIITDS \\
25 & NDIITDSDGN \\
26 & ITDSDGNDKL \\
27 & SDGNDKLSFS \\
28 & NDKLSFSDSN \\
29 & LSFSDSNLKD \\
30 & SDSNLKDLTF \\
31 & NLKDLTFEKV \\
32 & DLTFEKVKHN \\
33 & FEKVKHNLVI \\
34 & VKHNLVITNS \\
35 & NLVITNSKKE \\
36 & ITNSKKEKVT \\
37 & SKKEKVTIQN \\
38 & EKVTIONWR \\
& \\
\hline
\end{tabular}

\begin{tabular}{|c|c|}
\hline $\begin{array}{l}\text { Peptide } \\
\text { number }\end{array}$ & $\begin{array}{l}\text { Peptide } \\
\text { sequence }\end{array}$ \\
\hline $39 *$ & TIQNWFREAD \\
\hline $40^{\star}$ & NWFREADFAK \\
\hline 41 * & READFAKEVP \\
\hline $42^{\star}$ & DFAKEVPNYK \\
\hline $43^{*}$ & KEVPNYKATK \\
\hline $44^{*}$ & PNYKATKDEK \\
\hline $45^{\star}$ & KATKDEKIEE \\
\hline $46^{*}$ & KDEKIEEIIG \\
\hline $47^{*}$ & KIEEI IGQNG \\
\hline $48 *$ & E I IGQNGER I \\
\hline $49^{*} \dagger$ & GQNGERITSK \\
\hline $50 * \dagger$ & GER I ISKQVD \\
\hline $51 t$ & ITSKQVDDII \\
\hline $52 t$ & KQVDDLIAKG \\
\hline $53 t$ & DDLIAKGNGK \\
\hline $54 t$ & IAKGNGKITQ \\
\hline $55 t$ & GNGKI TQDEL \\
\hline $56 t$ & KITQDELSKV \\
\hline $57 t$ & QDELSKVVDN \\
\hline $58 t$ & LSKVVDNYEL \\
\hline $59 t$ & VVDNYELLKH \\
\hline $60 t$ & NYELLKHSSK \\
\hline $61 t$ & LLKHSKNVTN \\
\hline 62 & HSKNVTNSLD \\
\hline 63 & NVTNSLDKLI \\
\hline 64 & NSLDKLISSV \\
\hline 65 & DKL ISSVSAF \\
\hline 66 & ISSVSAFTSS \\
\hline 67 & VSAFTSSNDS \\
\hline 68 & FTSSNDSRNV \\
\hline 69 & SNDSRNVLVA \\
\hline 70 & SRNVLVAPTS \\
\hline 71 & VLVAFTSNLD \\
\hline 72 & APTSNLDQSL \\
\hline 73 & SMLDQSLSSL \\
\hline 74 & DQSLSSLQEA \\
\hline 75 & LSSLQFAPAA \\
\hline
\end{tabular}
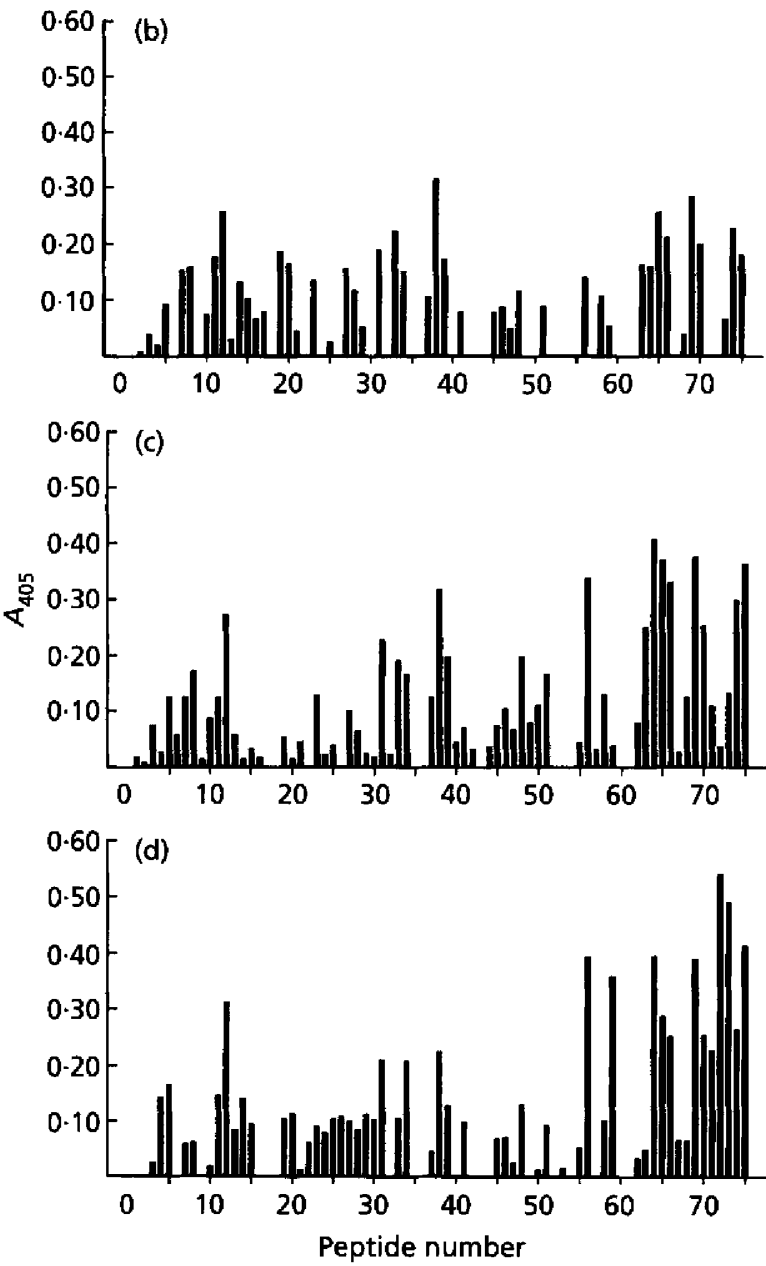

Fig. 4. Epitope mapping of the $C$ terminus of LktA(A1) encompassing amino acid residues $722-953$. A set of 75 overlapping 10 amino acid peptides was synthesized on a solid phase. The sequences of individual peptides are shown in (a). The positions of epitopes for mAbs MM601 and MM605 as defined in Fig. 3 are indicated by * and t. respectively. The reactivities of these peptides in ELISA with three antisera are shown in (b)-(d). (b) SPF lamb anti-LktA' (C-terminal polypeptide-LacZ $\alpha$ fusion protein encoded by pAL12), (c) SPF lamb anti-LktA(A1) encoded by pAL2 and (d) sheep anti-A1 live cells.

serum raised in an SPF lamb against the full-length recombinant LktA(A1) expressed from plasmid pAL2 (anti-LktA) (Fig. 4c) and sheep SA1 antiserum developed after an active infection with $P$. baemolytica serotype A1 (Fig. 4d). SPF lamb pre-immune sera and a conjugate control produced no significant reaction with these 
Table 2. Neutralizing titres of absorbed and non-absorbed polyclonal antisera SA1 or $\$ 791$ and the strength of reactions with recombinant LktA (pAL2 product) by immunoblotting

\begin{tabular}{|ccccc|}
\hline & \multicolumn{2}{c}{ SA1 antiserum } & \multicolumn{2}{c|}{ S791 antiserum } \\
\cline { 2 - 5 } & $\begin{array}{c}\text { Neutralizing Immunoblot } \\
\text { titre* }\end{array}$ & $\begin{array}{c}\text { Neutralizing } \\
\text { reactivity } t\end{array}$ & $\begin{array}{c}\text { Immunoblot } \\
\text { reactivity }\end{array}$ \\
\hline Pre-immune & - & - & - & - \\
Pre-absorption & 1280 & ++++ & 80 & ++++ \\
Absorption 1 & $\mathrm{NT}$ & ++++ & $\mathrm{NT}$ & ++++ \\
Absorption 2 & 640 & ++ & 80 & ++ \\
Absorption 3 & 640 & $+/-$ & 80 & $+/-$ \\
Absorption 4 & 640 & - & 80 & $+/-$ \\
\hline
\end{tabular}

* NT, Not tested.

$\uparrow$ The strength of reaction on immunoblots was graded from nil $(-)$ to very strong $(++++)$.

peptides. The deduced positions of the epitope for $\mathrm{mAb}$ MM601 (peptides 39-50) and mAb MM605 (peptides 49-61) are indicated (Fig. 4a).

\section{Antibodies with specificity for non-linear epitopes are identified in convalescent antisera}

Denatured full-length recombinant $\mathrm{LktA}(\mathrm{A} 1)$ immobilized on a solid phase was used to absorb out specific antibodies from a homologous antiserum SA1 (anti-A1 serotype antiserum in response to infection) and from a heterologous antiserum $\mathrm{S} 791$ (anti-A2 serotype antiserum in response to infection). The results of absorptions of these SA1 and S791 antisera were similar (Table 2).

The antibodies directed against the linear epitopes in these antisera were quantified by their reaction with denatured recombinant LktA(A1) on immunoblots. The amounts of these antibodies were significantly reduced by the absorption procedure to the point that an immunoblotting reaction could not be detected in absorbed antiserum at $1 / 40$ dilution. However, antibody absorptions did not produce proportional reductions in their LktAneutralizing capacities, which was reduced by approximately $50 \%$ of the non-absorbed antiserum level in the case of SA1 antiserum and was unaffected for the S791 antiserum. Neutralization capacity found in absorbed antiserum was attributed to the presence of LktAneutralizing antibodies directed against non-linear epitopes. Neutralization due to non-specific factors present in the antisera were not indicated since S791 and SA1 pre-immune sera did not react with $\operatorname{LkA}(\mathrm{A} 1)$ on immunoblots and had no toxin-neutralizing capacities.

\section{DISCUSSION}

'These results showed that both linear and conformational epitopes within LktA(A1) are involved in antibodymediated toxin neutralization and that a defined fragment of $\mathrm{LktA}(\mathrm{A} 1)$ is a potential vaccine component.
Vaccination experiments have established that crude preparations of native LktA can play an important role in protective immunity to ovine pasteurellosis (Sutherland $t$ al., 1989) and bovine pasteurellosis (Shewen et al., 1988; Rice-Conlon et al., 1995) and that a purified recombinant LktA can significantly enhance the protective capacity of a vaccine containing other cellular components (Conlon $e^{t}$ al., 1991). A positive correlation has also been demonstrated between serum anti-LktA antibody titres and protective immunity (Mosier et al., 1986, 1989) and between toxin-neutralizing antibody titre and protective immunity (Gentry et al., 1985; Sutherland et al., 1989; Rice-Conlon et al., 1995). Thus, antibody-mediated toxin neutralization provides a plausible means by which the pathogenicity of $P$. baemolytica may be reduced in vivo.

Gentry \& Srikumaran (1991) and Gerbig et al. (1992) demonstrated that a $\mathrm{mAb}$ can neutralize $\mathrm{L} \mathrm{kt} \mathrm{A}(\mathrm{Al})$ in vitro. Pellett et al. (1990) also demonstrated that a structurally related RTX toxin, $\alpha$-haemolysin of $E$. coli, could be neutralized by an anti-Lkt $A$ monoclonal antibody. Hence, the possibility arises that an LktA-derived peptide containing either a single epitope or a limited set of epitopes might be an effective component of a $P$. baemolytica vaccine.

\section{The location of an epitope recognized by an LktA- neutralizing antibody}

The monoclonal antibodies described here were from two independent cell fusions and were raised against either recombinant LktA (JM1-JM6) or native LktA (mAbs MM601 and MM605; Gentry \& Srikumaran (1991). Each of these antibodies reacted with full-length recombinant LktA(A1) and with defined polypeptides derived from LktA(A1) indicating that their epitopes lay within a 229 amino acid region at the $C$-terminal end of the toxin. Since these monoclonal antibodies recognized denatured LktA(A1) on immunoblotting, they are probably specific for linear sequences of amino acids.

Although the mAbs JM1-JM6 reacted strongly with this 
C-terminal polypeptide of $\mathrm{LktA}(\mathrm{A} 1)$, they showed no neutralizing activity. This demonstrates that there are antigenic regions within the polypeptide which are not targets for neutralizing antibodies. More detailed mapping with the two mAbs raised to native toxin localized the epitope for the strongly neutralizing $\mathrm{mAb}$ to a 32 amino acid region neat the $\mathrm{C}$-terminus of $\mathrm{LktA}(\mathrm{A} 1)$ (residues 841-872) and that for the non-neutralizing $\mathrm{mAb}$ to a 33 amino acid region immediately adjacent (residues 873-905). The close proximity of epitopes for two mAbs with distinctly different neutralizing capacities supports a model, such as that proposed by Forestier \& Welch (1991), for the existence of distinct functional domains within the P. baemolytica LktA(A1) molecule. An attempt to map the location of the epitope of the neutralizing $\mathrm{mAb}$ at higher resolution by scanning a series of synthetic peptides was unsuccessful because the $\mathrm{mAb}$ failed to react. The reason for the failure is unclear but may reside in the specificity of the $\mathrm{mAb}$ for a spatial arrangement in the epitope which cannot be reproduced in a short synthetic peptide. However, a more precise location of this epitope could be deduced from comparison of the amino acid sequences of $\operatorname{Lkt} A(\mathrm{~T} 10)$ and $\operatorname{LktA}(A 1)$. Since the neutralizing $\mathrm{mAb}$ reacted with $\mathrm{Lkt} A(\mathrm{~A} 1)$ but not $\mathrm{Lkt} A(\mathrm{~T} 10)$ the epitope must lie in the region whcre the amino acid sequences differ, for example residues 845 to 859 . Gerbig et al. (1992) similarly localized an epitope for a neutralizing $\mathrm{mAb}$ to the C-terminal region of LktA(A1). This epitope was implicated in target cell recognition or binding.

\section{Immunogenicity of recombinant LktA(A1)-derived polypeptides}

The presence of a neutralizing epitope in the C-terminal region of $\mathrm{Lkt}(\mathrm{A} 1)$ led us to examine its immunogenic properties and potential as a vaccine component. Fulllength recombinant LktA(A1) (expressed from plasmid $\mathrm{p} \Lambda \mathrm{L} 2)$ and a recombinant $\mathrm{Lkt} A(\mathrm{~A} 1)$-derived polypeptide (expressed from plasmid pAL12) both evoked antibody responses in SPF lambs with LktA-neutralizing activity. By reacting these antisera with the same set of synthetic peptides described above, it was possible to determine the distribution of reactive epitopes within the $\mathrm{C}$-terminal region of Lkt $A(A 1)$. Both antisera produced a complex distribution pattern indicating that several epitopes lie in this region. The pattern produced by these antisera and by an antiserum (SA1) obtained by exposure of a sheep to live cells of $P$. baemolytica serotype A1 corresponded closely. Thus, the route of exposure and form in which the antigen was presented did not greatly affect the profile of the antibody response to the linear epitopes present at the C-terminus of LktA.

Among this set of linear epitopes it was not possible to determine which are specifically involved in neutralization. However, it was possible to identify an epitope in a position corresponding to the epitope defined by the toxin-neutralizing $\mathrm{mAb}$.

Mapping epitopes involved in antibody-mediated toxin neutralization on the basis of examining the immunological response to defined peptides proved to be im- practical; small LktA-derived recombinant polypeptides expressed from plasmids pAL34 and pAL36, which contained the neutralizing epitope were found not to be immunogenic in rabbits. Further investigation of methods of antigen presentation of these peptides is warranted.

\section{Are conformational epitopes involved in neutralization of LktA?}

In a natural infection with $P$. baemolytica it is likely that the host immune system produces antibodies which are directed against both linear and non-linear epitopes of Lkt A. We have been able to directly identify the distribution of linear epitopes; however, it is more difficult to locate conformational epitopes and epitopes generated by post-translational modification of LktA(A1) and to determine their role in antibody-mediated neutralization.

Whilst the form of antigen presentation does not appear to have a marked effect on the immunological response to linear epitopes at the $C$ terminus of $\operatorname{Lkt} A$, it is likely that this will greatly affect the response to conformational epitopes. For example, during nasal carriage or natural infection with $P$. baemolytica, the host animal may be exposed to LktA in its native conformation for an extended period of time. In contrast, vaccination with recombinant or denatured LktA may produce antibodies which are predominantly directed against linear epitopes, although the extent to which the molecule can spontaneously refold into its native configuration in a vaccine is unknown.

We used antibody absorption to selectively remove the antibodies directed against lincar epitopes from polyclonal antisera and then quantified the Lkt $\Lambda$-neutralizing capacity of the remaining antibodies, which presumably react with non-linear epitopes. This showed that in a natural infection antibodies are produced against linear and non-linear epitopes and that both can play a role in toxin neutralization. Whether a single epitope mediates neutralization in vivo or whether neutralization requires concerted interaction with several epitopes is presently unknown and should be examined in any future work.

\section{ACKNOWLEDGEMENTS}

We acknowledge the technical assistance of Mr K. Aitchison, and the financial support of the Scottish Office Agriculture, Environment and Fisheries Department and Hoechst Animal Health, UK in this work.

\section{REFERENCES}

Adusu, T. E., Conlon, P. D., Shewen, P. E. \& Black, W. D. (1994). Pasterurella baemolytica leukotoxin induces histamine release from bovine pulmonary mast cells. Can $J$ Vet Res 58, 1-5.

Breider, M. A., Kumar, S. \& Corstvet, R. E. (1991). Interaction of bovine neutrophils in Pasteurella baemolytica mediated damage to pulmonary endothelial cells. Vet Immunol Immunopathol 27, 337-350.

Conlon, J. A., Shewen, P. E. \& Lo, R. Y. (1991). Efficacy of recombinant leukotoxin in protection against pneumonic challenge with live Pasteurella baemolytica A1. Infect Immun 59, 587-591. 
Czuprynski, C. J., Noel, E. J. \& Adlam, C. (1991a). Interaction of bovine alveolar macrophages with Pasteurella baemolytica A1 in vitro: modulation by purified capsular polysaccharide. Vet Microbiol 26, 349-358.

Czuprynski, C. J., Noel, E. J., Ortiz-Carranza, O. \& Srikumaran, $\mathbf{5}$ (1991b). Activation of bovine neutrophils by partially purified Pasteurella baemolytica leukotoxin. Infect Immun 59, 3126-3133.

Donachie, W. \& Gilmour, N. J. L. (1988). Sheep antibody response to cell wall antigens expressed in vivo by Pasteurella baemolytica serotype A2. FEMS Microbiol Lett 56, 271-276.

Donachie, W., Gilmour, N. J. L., Mould, D. L. \& Poxton, I. R. (1984). Comparison of cell surface antigen extracts from two serotypes of Pasteurella baemolytica. J Gen Microbiol 130, 1209-1216.

Fenwick, B.W. (1990). Virulence attributes of the lipopolysaccharide of the HAP group of organisms. Can J Vet Res 54, $\mathrm{S} 28-\mathrm{S} 32$.

Forestier, C. \& Welch, R. A. (1991). Identification of R'TX toxin target cell specificity domains by use of hybrid genes. Infect Immun 59, 4212.4220 .

Fraser, J., Gilmour, N. J. L., Laird, S. \& Donachie, W. (1982). Prevalence of Pasteurella baemolytica serotypes isolated from ovine pasteurellosis in Britain. Vet Record 110, 560-561.

Frey, J. (1995). Exotoxins of Actinobacillus pleuropnetmoniat. In Haemopbilus, Actinobacillus and Pasteurella, pp. 101-104. Fdited by W. Donachie, F. A. Lainson \& J.C. Hodgson. New York: Plenum.

Gentry, M. J. \& Srikumaran, S. (1991). Neutralizing monoclonal antibodies to Pasteurella baemolytica leukotoxin affinity-purify the toxin from crude culture supernatants. Microb Pathog 10, 411-417.

Gentry, M. J., Confer, A. W. \& Panciera, R. J. (1985). Serum neutralization of cytotoxin from Pasteurella baemolytica, serotype 1 and resistance to experimental bovine pneumonic pasteurellosis. Vet Immun Immmopath 9, 239-250.

Gerbig, D. G., Cameron, M. R., Struck, D. K. \& Moore, R. N. (1992). Characterization of a neutralizing monoclonal antibody to Pasteurella baemolytica leukotoxin. Infect Immun 60, 1734-1739.

Geysen, H. M., Rodda, S. J., Mason, T. J., Tribbick, G. \& Schoofs, P. G. (1987). Strategies for epitope analysis using peptide synthesis. $J$ Immunol Methods 102, 259-274.

Gilmour, N. J. L. \& Gilmour, J. S. (1989). Pasteurellosis of sheep. In Pasteurella and Pasteurellosis, pp. 223-262. Edited by C. Adlam \& J. M. Rutter. London: Academic Press.

Gilmour, N. J., Donachie, W., Sutherland, A. D., Gilmour, J. S., Jones, G. E. \& Quirie, M. (1991). Vaccine containing iron-regulated proteins of Pastearella haemolytica A2 enhances protection against experimental pasteurellosis in lambs. Vaccine 9, 137-140.

Highlander, S. K., Chidambaram, M., Engler, M. J. \& Weinstock, G. M. (1989). DNA sequence of the Pastetrella baemolytica leukotoxin gene cluster. DNA 8, 15-28.

Kohler, G. \& Milstein, C. (1975). Continuous cultures of fused cells secreting antibody of predefined specificity. Nature 256, 495-497.

Lo, R. Y. C. (1995). Molecular studies of antigens in HAP organisms. In Haemopbilus, Actinobacillus and Pasteurella, pp. 129-142. Edited by W. Donachic, F. A. Lainson \& J. C. Hodgson. New York: Plenum.

Lo, R. Y. C., Strathdee, C. A. \& Shewen, P. E. (1987). Nucleotide sequence of the leukotoxin genes of Pasteurella baemolytica A1. Infect Immun 55, 1987-1996.
Maheswaran, S. K., Weiss, D. J., Kannan, M. S., Townsend, E. L., Reddy, K. R., Whiteley, L. O. \& Srikumaran, S. (1992). Effects of Pasteurella baemolytica A1 leukotoxin on bovine neutrophils: degranulation and generation of oxygen-derived free radicals. Vet Immunal Immunopatbol 33, 51-68.

Mosier, D. A., Confer, A. W., Hall, S. M., Gentry, M. J. \& Panciera, R. J. (1986). Enzyme-linked immunosorbent assay for detection of serum antibodies to Pasteurella baemolytica cytotoxin (leukotoxin) in cattle. J Clin Mirrobiol 24, 218-222.

Mosier, D. A., Simons, K. R., Confer, A. W., Panciera, R. J. \& Clinkenbeard, K. D. (1989). Pasteurella baemolytica antigens associated with resistance to pneumonic pasteurellosis. Infect Immun 57, 711-716.

Murray, J. E., Davies, R. C., Lainson, F. A., Wilson, C. F. \& Donachie, W. (1992). Antigenic analysis of iron-tegulated proteins in Pasteurella baemolytica $\mathrm{A}$ and $\mathrm{T}$ biotypes by immunoblotting reveals biotype-specific epitopes. / Gen Microbiol 138, 283-288.

Ogunnariwo, J. A. \& Schryvers, A. B. (1990). Iron acquisition in Pasteurella haemolytica: expression and identification of a bovinespecific transferrin receptor. Infect Immun 58, 2091-2097.

Pellett, S., Boehm, D. F., Snyder, I. S., Rowe, G. \& Welch, R. A. (1990). Characterization of monoclonal antibodies against the Escbericbia coli hemolysin. Infect Immun 58, 822-827.

Rice-Conlon, J. A., Gallo, G. F., Shewen, P. E. \& Adlam, C. (1995). The efficacy of a Pastewrella baemolytica A1 vaccine given as a single dose against experimental pneumonic challenge in cattle. In Haemopbilus, Actinobacillus and Pastewrella, pp. 101-104. Edited by W. Donachie, F. A. Lainson \& J. C. Hodgson. New York: Plenum.

Rowe, G. E., Pellett, S. \& Welch, R. A. (1994). Analy sis of toxigenic functions associated with the RTX repeat region and monoclonal antibody D12 epitope of Escherichia coli hemolysin. Infert Immun 62, $579-588$.

Sambrook, J., Fritsch, E. F. \& Maniatis, T. (1989). Molecular Cloning: a Laboratory Manual, 2nd edn. Cold Spring Harbor, NY: Cold Spring Harbor Laboratory.

Shewen, P.E. \& Wilkie, B. N. (1983). Pasteurella baemolytica cytotoxin: production by recognized serotypes and neutralisation by type-specific rabbit antisera. $A m J V e t \operatorname{Res} 44,715-719$.

Shewen, P., Sharp، A. \& Wilkie, B. N. (1988). Ffficacy testing a Pasteurella baemolytica extract vaccine. Vet Med 83, 10781083.

Sneath, P. H. A. \& Stevens, M. (1990). Actinobacillas rossi sp, nov, Actinobacillus seminis sp. nov., nom. rev., Pasteurella bettii sp. nov., Pasteurella lymphangitidis sp. nov., Pasteurella mairi sp. nov., and Pasteurella trehalosi sp. nov. Int I Syst Bacteriol 40, 148-153.

Sutherland, A. D., Donachie, W., Jones, G. E. \& Quirie, M. (1989). A crude cytotoxin vaccine protects sheep against experimental Pasteurella baemolytica serotype A2 infection. Vet Microbiol 19, 175-181.

Towbin, H., Staehelin, T. \& Gordon, J. (1979). Electrophoretic transfer of proteins from polyacrylamide gels to nitrocellulose sheets: procedure and some applications. Proc Natl Acad Si US $A$ $76,4350-4354$.

Wilkie, I. W., Fallding, M. H., Shewen, P. E. \& Yager, J. A. (1990). The effect of Pasteurella baemolytica and the leukotoxin of Pasteurella baemolytica on bovine lung explants. Can J Vet Res 54, 151-156.

Received 30 August 1995; revised 25 April 1996; accepted 7 May 1996. 